\title{
The O-Ring Sector and the Foolproof Sector: An explanation for cross-country income differences
}

\author{
Garett Jones \\ Department of Economics \\ and \\ Center for Study of Public Choice \\ George Mason University
}

This version:

February 2008

Preliminary and Incomplete: Do not cite. 
Why do skill differences that matter so little for individuals appear to matter so much for groups? In this paper, I offer one solution to this question. I contend that the average wage within a given country is pinned down by the productivity of its best workers in a Kremer-style (1993) "O-ring" sector. In this sector, high-skilled workers perform tasks that depend on strategic complementarities in production.

Other less-skilled workers in that same country aren't good enough to work in this "Oring" sector, but they can work in a conventional, diminishing-returns-to-labor "Foolproof" sector. Importantly, high-skilled workers can move between the O-ring and Foolproof sectors. The key assumption of this model is that the wage of high-skilled workers must be equal across the two sectors, a simple invocation of the law of one price.

Under this model, within a given country, the less-skilled workers will earn only slightly less than the highly-skilled workers, since, after all, in the Foolproof sector high- and low-skilled workers are close substitutes. But across countries, a nation whose best workers are slightly lower in quality will be much less productive, since it means that workers in that nation's "Oring" or "weak link" sector will produce much less.

This model builds on the idea that there are two kinds of jobs: Some jobs require a number of production steps where the product's value can be destroyed by one "weak link," (e.g., advanced manufacturing, high-level law or finance), while other jobs can be done quite well either by isolated individuals or by a combination of workers with a variety of skill levels (e.g., many personal services, food preparation, routine law and banking matters).

In general equilibrium the model generates results that match the data: Looking within a given country, the (modest) wage variance across workers will be driven entirely by differences 
within the Foolproof sector. But looking across countries, productivity variance will be driven entirely by (large) differences across the O-ring sectors.

But of course, all of this is for naught if the first sentence of this paper poses an invalid question. Is there evidence that skills and abilities matter little for individuals but a lot for groups?

Yes. For example, Hanushek and Kimko (2000) look at how national math and science scores predict long-run economic performance across countries; famously, East Asian economies combine high math and science scores with good economic performance. The authors show that average national math and science scores are excellent predictors of large differences in longterm economic performance even if they omit East Asian economies from their sample.

More importantly, they also show that such scores are weak predictors of how much typical immigrants from those countries earn when they arrive in the U.S.. Immigrants from high-scoring countries indeed earn more than immigrants from low-scoring countries, but the differences are quantitatively modest. Combining these two results, they conclude:

[T] he [cross-country] growth equation results are much larger than the corresponding results for individual earnings (Hanushek and Kimko, 2000, p. 1204).

Further, they find that these test score measures, which they consider indices of "labor quality," are more important than typical years-of-schooling measures for predicting cross-country economic performance:

The growth model results...imply that the externalities must be significantly stronger for quality than for quantity. The estimated growth effect of one standard deviation of quality is larger than would be obtained from over nine years in average schooling (Hanushek and Kimko, 2000, p. 1204). 
Jones and Schneider (forthcoming) find much the same when they use cross-country differences in IQ scores rather than Hanushek and Kimko's math and science tests. Immigrants from highaverage-IQ countries indeed earn more upon arrival in the U.S.. But while one IQ point predicts only one percent more U.S. income for an individual worker (a result supported by a variety of micro-level labor econometric evidence), a country with an average IQ score one point higher would be predicted to produce six to seven percent more output per worker. (Note that within a given country, one standard deviation in IQ is approximately 15 IQ points).

Separately, Jones and Schneider (2006) also find that once one controls for national average IQ in cross-country growth regressions, the statistical significance of education quantity measures is diminished, thus supporting Hanushek and Kimko's second contention that quality of labor matters more than quantity of education. Thus, Jones and Schneider support both of Hanushek and Kimko's claims: test scores matter more for nations than for individuals, and test scores matter more than education at the cross-country level.

Thus, in the model below, I will focus on showing how modest differences in "labor quality" will generate small intra-country differences, but large inter-country differences. Whether one considers math and science scores or Lynn and Vanhanen's $(2002,2006)$ national average IQ scores the preferred measure of labor quality is irrelevant to the model's interpretation. I will omit discussion of the quantity of education, since it doesn't appear to predict large cross-country income differences.

I will begin by setting up a benchmark model with two production sectors and two levels of labor quality within a given country. In the model, I never appeal to exogenous cross-country productivity differences to explain cross-country income differences. I then work through some simple quantitative exercises that show that the model can explain real-world data, and show that 
the model generalizes to a continuum of labor quality and to Kremer's expanded O-ring model that allows an endogenous choice of the length of the production process. I follow with a discussion of some of the model's implications for economic growth research, and conclude.

\section{The Benchmark Case}

\section{A. Model}

The O-ring production function is exactly that of Kremer (1993): Each firm combines an amount $k$ of capital with a group of $n$ workers to create output. Each worker performs her task accurately with a probability of $q$; another equivalent interpretation is that $q$ is the fraction of "potential value" that a particular worker actually creates, taking the quality of other workers as given. Kremer shows that in equilibrium, workers within a given firm will only be combined with other workers of the same skill level-something that I assume throughout. This endogenous sorting of workers is the source of the "strategic complementarity" contained within the Kremer model.

There will be a total of $\varphi$ firms in the O-ring sector, and the number $\varphi$ will be determined by the free entry condition, which in the benchmark equilibrium will depend only on the supply of willing, high-skilled workers.

Formally, output per firm, precisely following Kremer, is:

$$
\mathrm{Y}_{\mathrm{O} / \varphi}=\mathrm{Bk}^{\alpha} \mathrm{q}_{\mathrm{h}}{ }^{\mathrm{n}} \mathrm{n}
$$

$\mathrm{Y}_{\mathrm{O} / \varphi}$ denotes $\mathrm{O}$-ring sector output per firm. Here, $\mathrm{B}$ is an exogenous productivity factor identical across countries. In equilibrium, Kremer shows that the O-ring wage is simply a fraction (1- $\alpha)$ of per-firm output divided among the $n$ workers. All other returns accrue to owners of capital. Clearly, if $\mathrm{n}$ is large, small differences in the quality of workers can generate large differences in wages and output. 
Now we turn to the Foolproof sector. Output in the Foolproof sector is similarly straightforward: It is a diminishing returns sector with labor as the only flexible input-one can think of personal services that demand negligible capital as well as subsistence farming as examples. The key is that workers of different skill levels can be directly aggregated, something that cannot happen in the O-ring sector but which economists routinely do when using conventional Cobb-Douglas production functions. In the Foolproof sector, two mediocre gardeners can provide as much service as one excellent gardener.

The aggregate effective labor force in the Foolproof sector, $\hat{L}_{\mathrm{F}}$, consists of the number of workers of each skill level multiplied by the skill of that set of workers, added up over all skill levels $S$. Mathematically,

$$
\hat{L}_{\mathrm{F}}=\sum^{S} q_{S F} L_{S F}
$$

As noted above, in the Foolproof sector, output is subject to diminishing returns to labor. For simplicity, but without loss of generality, I assume that the labor share is the same across the two sectors, and I scale Foolproof productivity by $A$. The non-labor share can be interpreted as return to land or return to (free-entry-driven) entrepreneurs who invent plans to use Foolproof labor; in either event, non-labor income in this sector is distributed lump-sum to the representative consumer. Thus,

$$
\mathrm{Y}_{\mathrm{F}}=\mathrm{A}\left(\hat{L}_{\mathrm{F}}\right)^{1-\alpha}
$$

For workers of a given skill level, the competitive wage $\left(\mathrm{w}_{\mathrm{FS}}\right)$ will equal the marginal product of their class of labor,

$$
\mathrm{W}_{\mathrm{FS}}=(1-\alpha) \mathrm{A}\left(\hat{L}_{\mathrm{F}}\right)^{-\alpha} \mathrm{q}_{\mathrm{S}}
$$


The only other conditions are the size of each class of workers. I employ particular notation for high-skilled workers, all of which worker either in the O-ring or the Foolproof sectorthroughout, labor is supplied inelastically. Therefore,

$$
\mathrm{L}_{\mathrm{h}}=\mathrm{L}_{\mathrm{ho}}+\mathrm{L}_{\mathrm{hf}}
$$

As noted above, in this benchmark model, I assume that there is only one other class of workers, the unskilled. They number $L_{u}$, and each has a skill level of $q_{u}$. Thus, the total inelastically supplied labor force equals $\mathrm{L}_{\mathrm{h}}+\mathrm{L}_{\mathrm{u}}$.

\section{B. The role of capital}

As noted above, capital is used in the O-ring sector only-with automobile or computer chip or spinning jenny production being typical examples. Capital is used optimally, with the marginal product of capital equaling the rental rate. For simplicity, I take the rental rate as given and identical across countries. My preferred interpretation of this assumption is to consider this the steady-state of a typical Ramsey or even Solow model. Alternatively, one can think of this overall model as being of a small open economy. In any case, this pins down a unique marginal product of capital.

Note that since the O-ring function is a per-firm function, the marginal product of capital is determined via equation (1), not by summing over all firms; again, this follows Kremer (1993). Given rental rate of capital $r$, it is straightforward to show that (XXX) yield an equilibrium capital stock (see Kremer for derivation) of

$$
\left(\frac{\alpha q^{n} n B}{r}\right)^{\frac{1}{1-\alpha}}
$$


Since $q^{n}$ appears in both the equilibrium wage and the equilibrium capital expressions, this means that differences in worker skill across countries will have a multiplier effect through the capital stock. We shall see that this makes it particularly valuable to have skilled workers working in the O-ring sector rather than in the Foolproof sector.

\section{General Equilibrium}

The key general equilibrium condition is that workers must be free to move across the two sectors, if there is demand for workers across both sectors. As we shall see, in the benchmark case the only type of workers that firms in both sectors will ever want to hire will be workers of that country's very highest skill level-all other less-skilled workers will only find employment in the Foolproof sector. Begin with that key general equilibrium condition:

$$
(1-\alpha) \mathrm{Bk}^{\alpha} \mathrm{q}_{\mathrm{h}}{ }^{\mathrm{n}}=(1-\alpha) \mathrm{A}\left(\hat{L}_{\mathrm{F}}\right)^{-\alpha} \mathrm{q}_{\mathrm{h}} \quad(\mathrm{XXX})
$$

Given everything but $\hat{L}_{\mathrm{F}}$, it's straightforward to solve this for $\hat{L}_{\mathrm{F}}$. This is the quality-weighted demand for labor in the Foolproof sector. Who will fill these jobs?

I've assumed that all labor is supplied inelastically, so everyone will work somewhere. As long as (XXX) holds, every single unskilled worker will work in the Foolproof sector, since that's the only place for them to work (For simplicity of notation, I refer to all workers who are below the highest skill level as "unskilled," and denote it by $\hat{L}_{\mathrm{UF}}$, and have aggregate skill level of $q_{u}$. This gives us only two classes of workers, $U$ and $H$ ). That means that $\mathrm{L}_{u}$ workers will provide $\mathrm{q}_{\mathrm{u}} \mathrm{L}_{\mathrm{u}}$ units of effective labor. Once all of them are in the Foolproof sector, then, at the margin, high-skilled workers are drawn over from the O-ring sector, until $\hat{L}_{\mathrm{F}}$ units of effective labor are supplied. So $\mathrm{L}_{\mathrm{hf}}$ high-skilled workers are in the Foolproof sector (each providing $\mathrm{q}_{\mathrm{h}}$ units of effective labor), while $\mathrm{L}_{\mathrm{ho}}$ workers are in the O-ring sector. 
One can solve this expression for $\hat{L}_{\mathrm{F}}$, substituting the equilibrium capital stock, to derive the demand for aggregate effective labor given a skill level in the O-ring sector. The key question, then, is whether this equilibrium will hold. It will indeed, as long as the aggregate of unskilled effective labor is less than $\hat{L}_{\mathrm{F}}$ In other words, as long as there are at least a few highskilled workers working in the Foolproof sector, the general equilibrium condition holds. In this benchmark case, I assume that this condition holds; below, I explore the alternative, which has potentially policy-relevant consequences.

Thus, I solve from the Foolproof sector back to the O-ring sector, assuming throughout that $\mathrm{L}_{\mathrm{h}}>\hat{L}_{\mathrm{F}}-\hat{L}_{\mathrm{UF}}>0$. This way, enough high-skilled workers are around to fill at least some jobs in both sectors. In this case $\hat{L}_{\mathrm{UF}}$ workers earn an equilibrium wage of

$$
(1-\alpha) \mathrm{A}\left(\hat{L}_{\mathrm{F}}\right)^{-\alpha} \mathrm{q}_{\mathrm{U}} \quad(\mathrm{XXX})
$$

(Of course, this implies that in equilibrium, the ratio of skilled to unskilled wages is precisely $\mathrm{q}_{\mathrm{h}} / \mathrm{q}_{\mathrm{u}}$ ). Total Foolproof output then equals $\mathrm{Y}_{\mathrm{F}}$, which is uniquely pinned down by the level of aggregate effective labor demand.

What of the O-ring sector? As noted before, O-ring firms expand meet the supply of high-skilled labor, $\mathrm{L}_{\mathrm{ho}}=\mathrm{L}_{\mathrm{h}}-\mathrm{L}_{\mathrm{hf}}$. The number of firms equals

$$
\varphi=\mathrm{L}_{\mathrm{ho}} / \mathrm{n}
$$

Since output is proportional to the number of firms, each of which produces according to (XXX), then $Y_{O}=B^{\alpha}{ }^{n}(n \varphi)$, and hence

$$
\mathrm{Y}_{\mathrm{O}}=\mathrm{Bk}^{\alpha} \mathrm{q}_{\mathrm{h}}{ }^{\mathrm{n}} \mathrm{L}_{\mathrm{ho}}
$$

Aggregate output equals $\mathrm{Y}_{\mathrm{O}}+\mathrm{Y}_{\mathrm{F}}$, and output per worker equals $\left(\mathrm{Y}_{\mathrm{O}}+\mathrm{Y}_{\mathrm{F}}\right) /\left(\mathrm{L}_{\mathrm{h}}+\mathrm{L}_{\mathrm{u}}\right)$.

Note that while one could add in the representative agent's preferences across goods as part of the general equilibrium setup, this would be inconsequential, since each sector's output is 
already completely determined by the labor demand in the two sectors. Thus, allocation of output across goods at a point in time is independent of consumer preferences, as long as the preferences allow some substitutability across the two types of goods.

\section{Discussion of the model}

\section{A. General Discussion}

In this Foolproof/O-ring model, the wage of skilled labor in both sectors is entirely pinned down by worker productivity in the O-ring sector. Meanwhile, the effective quantity of skilled labor demanded is entirely pinned down by the quantity demanded of aggregate labor at the equilibrium skilled wage minus the effective quantity supplied of unskilled labor (all of whom will work).

Informally, the skilled labor just fills up the gap between unskilled supply and aggregate labor demand. Thus, equilibrium wage and quantity are pinned down in two separate markets.

But why won't unskilled labor find its way into the O-ring sector? After all, the promise of increasing returns should lure workers away from the relatively disappointing Foolproof sector, shouldn't it? The answer flows directly from (XXX), Kremer's O-ring production function. Consider a case where $\mathrm{q}_{\mathrm{h}}=1$ and $\mathrm{q}_{\mathrm{u}}=0.9$, as in the simulations below. Even if there are only two links in the O-ring production chain, and even if I ignore the multiplier effect of capital, two unskilled workers will produce only $0.9^{2}=81 \%$ as much as two high-quality workers. In the Foolproof sector, an unskilled worker will produce $90 \%$ as much as a skilled worker, and will earn $90 \%$ of the wage of skilled worker-so of course she will stay in the Foolproof sector. 


\section{B. An interesting exception: Workers out of reach of the $\mathbf{O}$-ring.}

The only way that unskilled workers will prefer to work in the O-ring sector is if there are so many unskilled workers that they alone create so much labor supply that the equilibrium skilled wage is pushed far below the O-ring wage. Note that they key assumption of the model, mentioned in the first page of this paper, is that skilled workers move freely and voluntarily between the two sectors, pinning down an identical skilled wage in both sectors. But if unskilled labor $\left(\mathrm{L}_{\mathrm{u}}\right)$ is so massive that

$$
(1-\alpha) B k^{\alpha} q_{h}{ }^{n}>(1-\alpha) A\left(q_{u} L_{u}\right)^{-\alpha} q_{h}
$$

then we are in a new world. If there are only a few too many unskilled workers, then all unskilled workers will work in the Foolproof sector. But, to take our capital-free example in the previous section, if the supply of unskilled labor is so large that the unskilled wage falls dramatically, it's possible that even the unskilled workers will be drawn into the O-ring sector, working at $81 \%$ of the skilled wage. In such a case,

$$
(1-\alpha) B^{\alpha}{ }^{\alpha}{ }_{u}{ }^{n}=(1-\alpha) A\left(q_{u} L_{u}\right)^{-\alpha} q_{u} .
$$

In this case, the unskilled workers would be in the same position as the skilled workers in the benchmark model: They would freely move between the two sectors in order to keep the wage in equilibrium.

In principle, this could lead to interesting discontinuities in aggregate output: If there are only a few too many unskilled laborers in an economy, these workers would all work in the simple Foolproof sector, while if there were vast numbers of unskilled workers, some of them would work in a highly-productive O-ring sector that was one rung down on the economic ladder. Thus, an image presents itself: The O-ring sectors as rungs on an economic ladder, with the Foolproof sector as the spaces between the rungs. 
This could explain why in some of the world's immigrant-heavy rich countries income inequality has recently increased: Large numbers of less-skilled workers could be pushing Foolproof-sector skilled wages down below the equilibrium condition of (XXX), thus either putting unskilled workers "below the rung" or even "down to the next rung" on the economic ladder. In either case, the ratio of skilled and unskilled wages would differ by a factor of more than the $\mathrm{q}_{\mathrm{h}} / \mathrm{q}_{\mathrm{u}}$ implied by the benchmark model.

If this is were case, we would expect to see skilled workers devoted completely to O-ring jobs. Further, we would see unskilled workers devoted either to Foolproof-type jobs or O-ring jobs of much lower productivity-clear testable implications of the model.

But in the benchmark case, which assumes either a low supply of or a high demand for unskilled Foolproof workers, no such "multiple ladder-rung” effect exists: All workers in the economy work at a wage that is closely tied to the wages in the skilled workers' O-ring sector.

\section{Econometric implications.}

Two key empirical results the flow from the benchmark model, which simply adds a diminishing returns "secondary labor market" to the O-ring model of Kremer.

1. When a labor econometrician estimates Mincer-style wage regressions within a given country whose data are generated by this model, she will find that the wage is precisely proportional to q, the skill of the worker. This is because the only variation in wages she will find will be across workers in the Foolproof sector, a sector that behaves in a conventional, neoclassical manner. 
2. When a macroeconometrician estimates cross-country productivity regressions across countries whose data are generated by this model, she will find a completely different result: Productivity differences for countries with different levels of $\mathrm{q}_{\mathrm{H}}$ will be vast-indeed, they will be even larger than in Kremer's O-ring model.

In Kremer's benchmark model, productivity per worker equaled $\mathrm{Bk}^{\alpha} \mathrm{q}^{\mathrm{n}}$, but in the benchmark Foolproof/O-ring model, the gap is much larger, for reasons I haven't yet discussed. This is because the O-ring sector is an increasing returns sector, one filled with positive productivity spillovers-something inherent in the use of the term "strategic complementarity." Each highskilled worker who is lured into the Foolproof sector reduces aggregate productivity dramatically. Holding A and B constant (the exogenous Foolproof/O-ring productivity parameters, respectively), this means this means that a fall in a nation's $\mathrm{q}_{\mathrm{h}}$ drives O-ring wages down dramatically, which makes the Foolproof sector all the more appealing as a place to work. This can cause a dramatic relative decline in that nation's GDP per worker, even for small declines in a nation's $\mathrm{q}_{\mathrm{h}}$.

\section{A quantitative example}

[discussion to be provided: see figure 3]

\section{Conclusion}

[to be provided] 
Figure 1: National Average IQ (Lynn \& Vanhanen, 2006) and Year 2000 GDP Per Worker

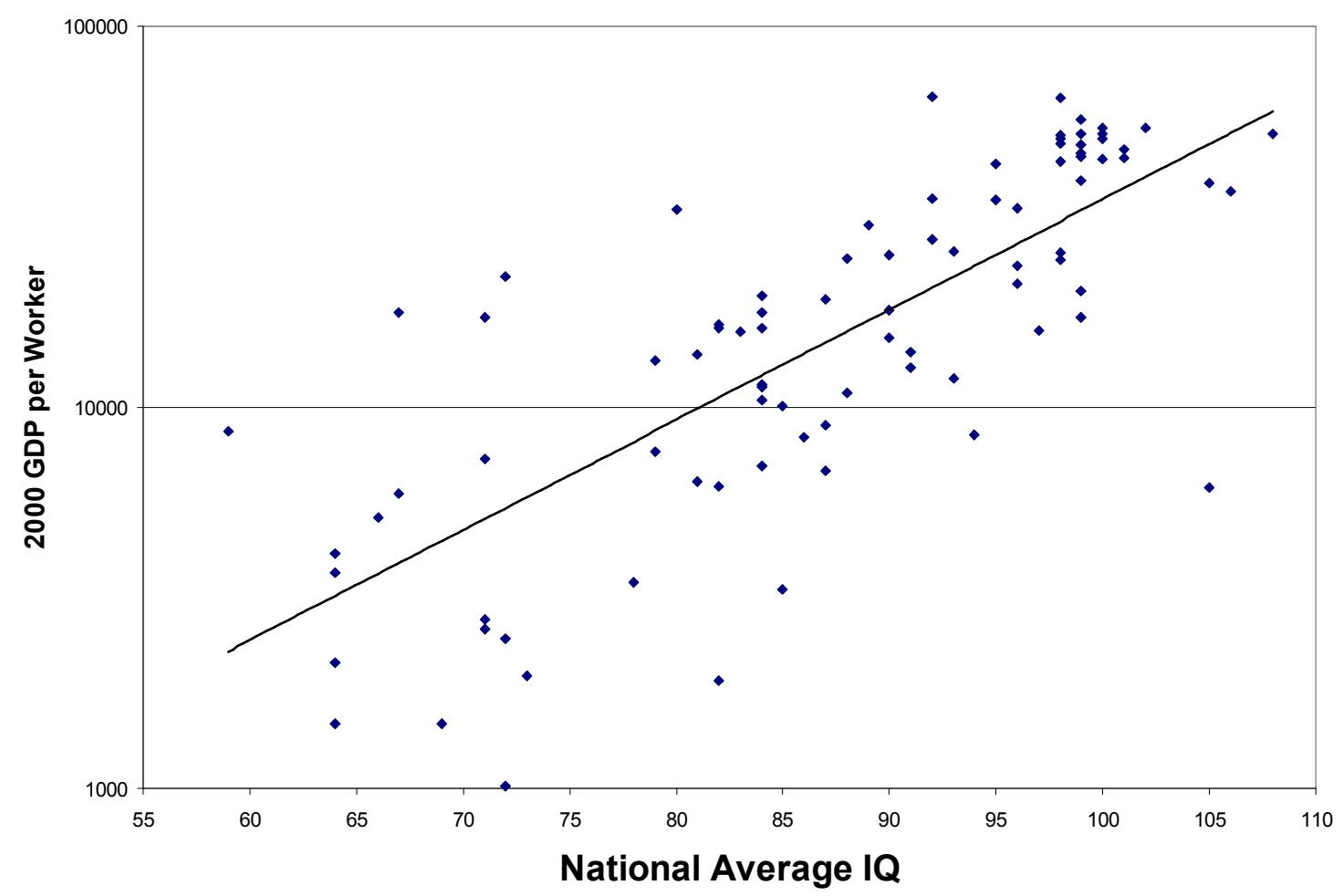

Notes: Y-axis shows GDP per worker in logarithmic scale. In this bivariate regression, the coefficient on national average IQ is 0.067 , and the $\mathrm{R}^{2}$ is $58 \%$. Thus, a one-point rise in IQ is associated with $6.7 \%$ higher output per worker. The sample covers 87 countries. The outlier in the lower-right corner is China ( $\mathrm{IQ}=105)$.

Source: Lynn and Vanhanen (2002) and Penn World Tables 6.1 for IQ and GDP data, respectively. 


\section{Figure 2}

\section{IQ and immigrant skill}

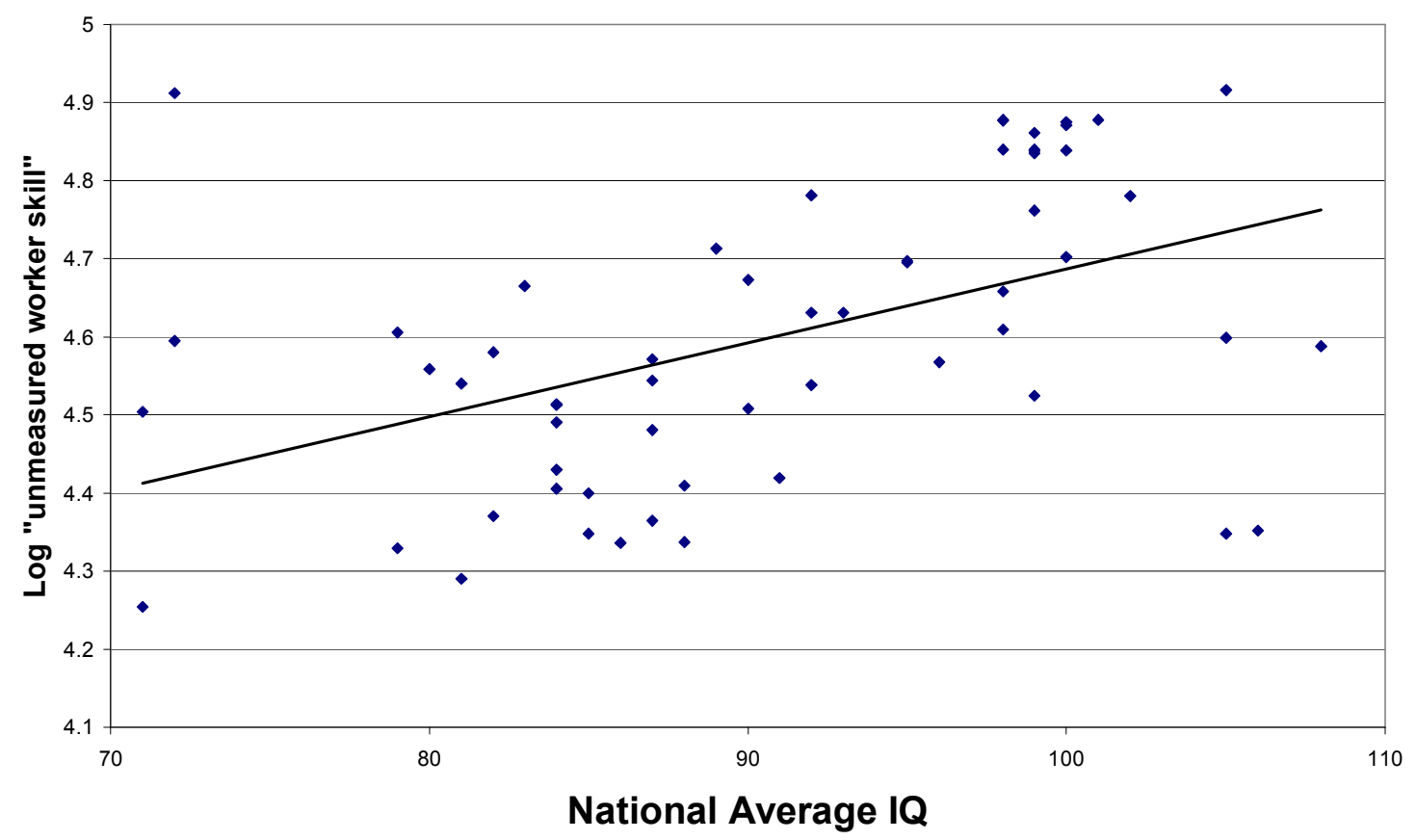

Notes: The x-axis reports estimates for national average IQ for country $i$ from Lynn and Vanhanen (2006). The y-axis reports values for $u w s_{i}$, the unmeasured worker skill estimate for immigrants from country $i$, as estimated in Hendricks (2002). $u w s_{i}$ is the log average wage of immigrants for country $i$, adjusting for age and education. The trendline reflects the OLS coefficient of 0.95 reported in the text, and the $\mathrm{R}^{2}$ is $22 \%$. 
Figure 3

\section{The impact of skilled worker quality in a Foolproof/O-ring economy}

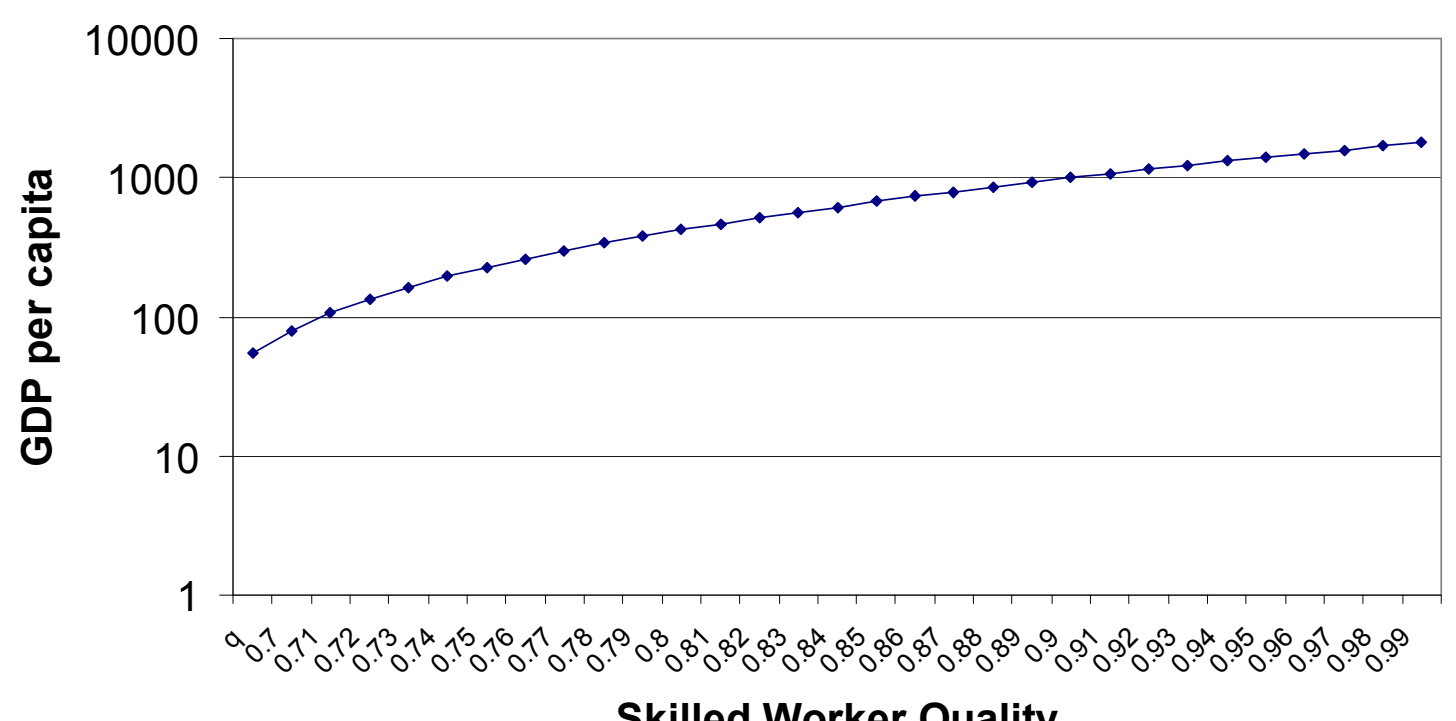

Notes: The $\mathrm{x}$-axis is the quality of skilled workers in a benchmark Foolproof/O-ring economy, and the $y$-axis is GDP per capita in that model economy. Thus, the value above 0.7 is the output in such an economy if the high-skilled workers had a skill level of 0.7 . Unskilled workers in a given country are always assumed to have a skill level $90 \%$ that of a skilled workers in that country. The supply of unskilled workers is $1 / 10^{\text {th }}$ that of skilled workers, $A=B=100$, and $n=3.8$. Holding the other values constant, a value of 3.8 was chosen to generate an outcome where GDP per capita was $32 \mathrm{X}$ higher in the $\mathrm{q}=1.0$ economy compared to the $\mathrm{q}=0.7$ economy. 
Bibliography

[to be provided] 